\title{
Nomofobi, Netlessfobi ve Gelişmeleri Kaçırma Korkusu: Sporcu Genç Yetişkinler Üzerine Bir Araştırma ${ }^{a}$
}

\author{
Kadir Yıldız ${ }^{\text {b, c, Dilara Kurnaz }}{ }^{\text {d }}$, Ali Murat Kırık
}

\section{Özet}

$\mathrm{Bu}$ araştırmada, lisanslı sporcuların akıllı telefon, internet bağımlılığı ve gelişmeleri kaçırma korkuları arasındaki ilişkinin incelenmesi amaçlanmıştır. Çalışma nicel araştırma yöntemlerinden betimsel ve ilişkisel tarama modelinde tasarlanmıştır. Çalışmaya, üniversitelerin spor eğitim kurumlarında öğrenim gören toplam 548 gönüllü lisanslı sporcu dahil edilmiştir. Veri toplama aracı olarak Nomofobi, İnternet bağımlılık ve Gelişmeleri Kaçırma Korkusu Ölçeği kullanılmıştır. Verilerin analizinde Independent $\mathrm{T}$ testi, One-Way Anova ve Çoklu doğrusal regresyon testi kullanılmıştır. Korelasyon analiz sonuçlarında ise gelişmeleri kaçırma korkusu, nomofobi ve internet bağımlılı̆̆ alt boyutları arasında orta düzeyde pozitif yönde ilişki tespit edilmiştir. Ayrıca gelişmeleri kaçırma korkusu ve nomofobinin internet bağımlığının önemli bir yordayıcısı olduğu söylenebilir. Sonuç olarak, yaşadığımız dijital çă̆, dijital bağımlılık ve benzeri bağımlılıkların ortaya çıkmasında önemli bir etkiye sahiptir. Bu bağımlılıklardan çözüm noktasında dijital detoks oldukça önemlidir. Dijital medya aracılığıyla yayılan metinleri, mesajları görselleri doğru okumak ve anlamlandırmak da son derece mühimdir.
Anahtar Kelimeler

Nomofobi

İnternet bağımlılı̆̆

Gelişmeleri Kaçırma korkusu

Genç yetişkinler

e-spor

Makale Hakkında

Geliş Tarihi: 02.01.2020

Kabul Tarihi: 24.04.2020

Doi: 10.18026/cbayarsos.669601

\section{Nomophobia, Netlessphobia and the Fear of Missing Developments: A Research on Young Adult Athletes}

\begin{abstract}
In this study, it is aimed to analyze the correlation among the addiction of smart phone, the internet addiction and the fear of missing developments of the licensed athletes. The study was designed in the descriptive and correlational survey models of the quantitative research method. 548 voluntary licensed athletes in total studying at sports education institutes of the universities. As data collection tool, Nomophobia, Internet addiction and Fear of Missing Developments Scale were used. Independent T test, One-way Anova and Multiple Linear Regression tests were used in the analysis of the data. The Correlation results revealed a medium and positive correlation between fear of missing developments, nomophobia and internet addiction subscales. Also it can be said that fear of missing development and nomofobia are an important estimators of internet addiction. As a result, the digital age that we live in has a significant effect on emergence of digital addiction and related addictions. It is also important that users should read and make sense of the texts, messages and images spread through digital media.
\end{abstract}

Keywords

\begin{tabular}{r} 
Nomophobia \\
Internet addiction \\
Fear of missing developments \\
Young adults \\
E-sport \\
About Article \\
\hline Received: 02.01 .2020 \\
Accepted: 24.04 .2020
\end{tabular}

Doi: 10.18026/cbayarsos.669601

\footnotetext{
a Bu çalışma, 13-16 Kasım 2019 tarihlerinde Antalya' da gerçekleştirilen 17. Uluslararası Spor Bilimleri Kongresinde Sözel sunum olarak sunulmuştur.

b İletişim Yazarı: kadiryildiz80@hotmail.com

c Doç. Dr., MCBÜ, Spor Bilimleri Fakültesi, https://orcid.org/0000-0003-3347-0319.

d Yüksek Lisans Öğrencisi, MCBÜ, Sosyal Bilimler Enstitüsü,, https://orcid.org/0000-0001-5616-4555

e Doç. Dr., Marmara Üniversitesi, İletişim Fakültesi, https://orcid.org/0000-0002-5771-4843.
} 


\section{Giriş}

Günümüzde bilgi ve iletişim teknolojilerindeki gelişmeler, 20. yüzyılın sonları ile 21. yüzyılın başlarında yaşanılan toplumsal değişimi ve bilgi toplumu kavramının önemini destekler niteliktedir. $\mathrm{Bu}$ dönem geleneksel sanayinin yerini bilgi teknolojilerine bıraktığı bilişim sektörünün ön planda olduğu ve ayrıca bireylerin sosyal ilişkilerinin yeniden tanımlandığı bir dönemi işaret etmektedir. Özellikle internet teknolojisinde yaşanan dönüşüm, toplumsal ilişkilerin de köklü bir şekilde değişikliğe uğramasına sebep olmuştur. Analog sistemlerden sayısal teknolojilere geçiş, sosyolojik yapıda da değişim meydana getirmiştir. Teknolojinin gelişim göstermesi birçok açıdan olumlu bir durum oluştursa da, bazı açılardan bakıldığında kimi sorunların yaşanmasına da sebebiyet vermektedir. Özellikle günümüzde bilginin taşıdığı rol ve önem her geçen gün artmakta, internet teknolojisi aracılığıyla tüm dünya geneline yayılan bilgi giderek güçlü bir potansiyele sahip olmaktadır.

Bireysel ve toplumsal değişimde, bilişim teknolojilerinin hayatın her noktasında etkisi olduğunu bilinen bir gerçek iken (Eryılmaz, 2018); bu araçların, bilginin metalaşma süreci ile birlikte bilginin yaratılması, depolanması ve dağıtılması için kolaylıklar sağladığı belirtilmiştir (Yıldız, 2016). 2019 yılı küresel internet kullanım raporları dikkate alındığında, bilginin yaygınlaşması ve depolanması sürecinin önemli bir unsur olduğu görülmektedir. Çünkü dünya nüfusunun 5.11 milyarı cep telefonu, 4.39 milyarı internet ve 3.26 milyarı ise mobil sosyal ağ kullanıcısı olarak karşımıza çıkmaktadır (Kemp, 2019). Bu dönüşüm süreci ister istemez bireyler üzerinde bir takım etkilere sebep olabilecektir. Bilgi ve iletişim teknolojilerinde yaşanılan hızlı gelişmeler özellikle internetin ve cep telefonlarının yaygınlaşması bireylerin yaşam biçimleri üzerinde ekonomik, sosyal, psikolojik ve hatta çevresel sorunlar da dâhil olmak üzere önemli etkiler bırakmaya başlamıştır (Eryılmaz, 2018). $\mathrm{Bu}$ sorunların başında yaşadığımız modern çağın korkuları olarak tanımlanan nomofobi, netlessfobi ve bunların ürünü olan gelişmeleri kaçırma korkusu karşımıza çıkmaktadır. İçinde bulunulan dijital çağ her yaştan her kesimden bireyi etkisi altına almakta, bu durum ister istemez bazı sorunların yaşanmasına sebebiyet vermektedir. Dijital hastalıklar çağın en temel problemi durumuna gelmiş, insan sağlığını derinden etkilemeye başlamıştır. Özellikle Z Kuşağı olarak tabir edilen 2000 ve sonrası doğan neslin bekleyen tehditler arasında Nomofobi, Netlessfobi ve FOMO olarak ifade edilen gelişmeleri kaçırma korkusu yer almaktadır. Özellikle sporla uğraşanlar için bu tarz hastalıklar önüne geçilmez sorunlar doğurmaktadır. Tıpkı sigara, tıpkı uyuşturucu bağımlılığı gibi teknolojik bağımlılık çocukları ve gençleri tehdit eder niteliktedir. Bu araştırmada, günümüzde özellikle genç yetişkinler olarak atfedebileceğimiz üniversitelerde öğrenim gören lisanslı sporcuların akıllı telefon, internet bağımlılığı ve gelişmeleri kaçırma korkularının incelenmesi amaçlanmıştır. Araştırmadan elde edilecek olası verilerin sporcular üzerindeki etkilerinin incelenmesi ve ilgili alan yazına katkı sağlaması beklenmektedir.

\section{Kavramsal Çerçeve}

\section{Internet Bağımlılı̆̆ı}

Bağımlılık kavramı, geleneksel olarak bir maddeye olan fiziksel bağımlılığı tanımlamada kullanılmasına rağmen (Holden, 2001), internetin aşırı kullanımı için de kullanılabilmektedir. Alanyazın araştırmalarında internet bağımlılığının; patolojik internet kullanımı (Davis, 2001) ve problemli internet kullanımı (Davis, Flett, \& Besser, 2002) gibi kavramlarla da kullanımını 
görmekteyiz. Bilgisayar bağımlılığı ise ilk kez 1991 yılında Shotton tarafından İngiltere'de çalışılmış olmasına rağmen, 1996 yılında Young tarafından Amerikan Psikologlar Birliği yıllık toplantısında tanıtılmıştır.

Yaşadığımız çağda dünya nüfusunun yarısından fazlasının aktif internet kullanıcısı olduğu ifade edilmektedir (Kemp, 2019). Bu duruma, internetin masaüstü bilgisayarla başlayan serüveninin diz üstü bilgisayar, tablet ve akıllı telefonlarla birlikte zirveye ulaşmasının önemli etkisi olduğu düşünülmektedir. Teknolojik gelişmelerin yeni nesil ürünü olan cep telefonlarının; bir amaç doğrultusunda zaman ve mekan sınırı olmadan insanları internetle buluşturmasının ve kesintisiz erişim imkanı sunmasının bilgi paylaşımı, iletişim kurma gibi olumlu etkilerinin (Eryılmaz, 2018), yanı sıra bireysel davranışlara yönelme eğilimi ve dolayısıyla yüz yüze iletişimde zayıflama, bilgi kirliliği, problemli kullanımlar, bağımlılık yaratan uygulamalar ve bunların ortaya çıkardığı sosyal, psikolojik ve ekonomik bir takım sorunlara da zemin hazırlamıştır (Bimber ve Copeland, 2013; Boulianne, 2015; Pea ve diğerleri, 2012; Tang ve Lee, 2013).Yaygın bir şekilde karşımıza çıkan bu sorunların, bireylerin toplumdan soyutlanmasına, iletişimden kopuk bireyler yetişmesinde ve sanal ortamlarda yaşamasına neden olabileceği söylenebilir.

Young (1998a) yapmış olduğu çalışmada bireylerin internet bağımlılıklarını tespit etmede sekiz kriterden bahsetmiştir.

- İnternet konusunda endişeli misiniz? (sürekli olarak interneti düşünme, internette yapılan aktivitelerin hayalini kurma, internette yapılması planlanan bir sonraki etkinliği düşünme, vb),

- Memnuniyeti sağlamak için giderek daha fazla oranda internet kullanma ihtiyacı hissediyor musunuz?

- İnternet kullanımını tekrar tekrar kontrol etmek, kesmek veya durdurmaya yönelik başarısız girişimler gösterdiniz mi?

- İnternet kullanımını azaltmaya veya durdurmaya çalışırken kendinizi huzursuz, karamsar, depresif veya sinirli hissediyor musunuz?

- İnternet'te başlangıçta planlanandan daha uzun süre mi kalıyorsunuz?

- İnternet nedeniyle önemli bir ilişkinin, işin, eğitim veya kariyer fırsatını tehlikeye soktunuz veya riske attınız mi?

- İnternete katılımın kapsamını gizlemek için ailenize, arkadaşlarınıza, terapistlere veya başkalarına yalan söylediniz mi?

- Interneti problemlerden kaçmanın bir yolu olarak mı yoksa olumsuz bir ruh halinden (çaresizlik, suçluluk, çökkünlük, kaygı) uzaklaşmak için mi kullanıyorsunuz?

Young (1998a) bu kriterlerden beş tanesinin bireylerde görülmesi durumunda bireylerin bağımlı olarak değerlendirilebileceğini ifade etmiştir. Ayrıca yapılan çalışmada aşırı internet kullanımının psikolojik uyarılma düzeyini, uyku düzenini, beslenme alışkanlıkları ile fiziksel aktivite durumunu olumsuz etkilediğini vurgulamıştır. Alan yazın araştırmalarında her ne kadar internet bağımlılığı ve netlessfobi kavramları birbirinin yerine kullanılsa da, netlessfobi kavramının internet bağımlılığının bir çıktısı olduğunu söylemek yanlış olmayacaktır.

\section{Netlessfobi}

Bilgi ve iletişim teknolojilerinde yaşanılan hızlı değişim günümüzde hemen hemen her yaştan bireyin gerek bilgi ve iletişim teknolojilerine gerekse internete erişimlerini de etkilemiştir. $\mathrm{Bu}$ gelişmelerle birlikte aslında bilgiye erişim ve iletişim kurma kolaylaşırken; internetin 
hayatımızın vazgeçilmez unsurlarından birisi haline gelmesi bireylerde dijital esarette diyebileceğimiz yoksun kalma korkusunun ortaya çıkmasına sebep olmaya başlamıştır.

Kisaca internetsiz kalma korkusu olarak nitelendirilen Netlessfobi (Being NetlessFobia) kavramı, "internetin aşırı kullanımından öte kişinin internetin olmadığı bir ortamda kalamaması ve internet yoksunluğundan endişe duyma (Öztürk, 2015)" durumu olarak tanımlanmaktadır. İnternetsiz kalma korkusu yaşayan bireylerde, internet bağımlılı̆̆ı ve diğer bağımlılık durumlarına benzer gerginlikler, sinirlilik ve öfkelenme gibi yoksunluklar görülebilir. Bu tür yoksunlukların görüldüğü bireylerin kendilerini sınırlamada ve kontrolde güçlük yaşayabilecekleri söylenebilir (Yıldız ve Yıldız, 2016).

Öztürk (2015), bir bireyin netlessfobik olarak tanımlanabilmesi için ne tek başına internette zaman geçirmesinin ne de daima online olarak akıllı telefon taşımasının yeterli olacağını ifade etmiştir. Ayrica bireyde internet bulunmayan ortamda huzursuz olması, internetsizlik neticesinde fiziksel tepkiler göstermesi, sürekli internet arayışı içerisinde olması, aklında daima bir profil güncelleme ya da kontrol etme arzusunun olması gerektiğini vurgulamıştır. Yapılan çalışmada Öztürk (2015), internet bağımlılığının belirtilerini;

- Kişisel kullanım için üçten fazla internet bağlantılı bilgisayar temelli cihazı aynı anda kullanmak,

- Sosyal alan tercihlerini wifi bağlantılı işletmelerden/mekanlardan yana kullanmaları,

- Günde 10 saatten fazla online olmaları,

- İnternet kesildiğinde hayatın durduğu inancına sahip olmaları,

- Internet kesildiğinde bir şeyleri kaçırdıkları ve yakalayamayacakları inancına sahip olmaları,

- İnternet bağlantılı cihazları uyurken dahi ulaşılabilir mesafede bulundurmaları,

- Bildiri, mesaj sesinden keyif almaları,

- İnternetten yoksun 1 saatten fazla kalamamaları,

- Günlük 20'den fazla sosyal amaçlı bildirimde bulunma,

- Reel alternatifler yerine sürekli olarak online olanları tercih etme(Gündelik işler, yemek sipariş, fatura ödeme... vb.),

- Nomofobik ve internet bağımlısı olmak, gibi gözlemlenebilir belirtiler olarak ifade etmişlerdir.

\section{Nomofobi}

İngilizce "No Mobile Phone Fobia"nın kısaltması olarak karşımıza çıkan Nomophobia, netlessfobia ile bağlantılı olan bir bozukluktur (Öztürk, 2015). Kavramsal olarak ise Nomopfobi, “cep telefonunun, kişisel bilgisayarm veya başka bir sanal iletişim cihazının bulunmamasından kaynaklanan rahatsızlık veya endişe" olarak tanımlanan özel bir fobidir (King vd., 2013). Kişisel bilgisayarları, tabletleri ve cep telefonlarını içeren bilgi ve iletişim teknolojilerinin ve sanal iletişimin artan kullanımı, bireylerin günlük alışkanlıklarında ve davranışlarında önemli değişikliklere neden olmaktadır. Öyle ki cep telefonları gerek eğlence gerekse iletişim ve sosyalleşme noktasında günümüzün vazgeçilmez popüler eğlence araçlarından birisi haline gelmiştir.

Nicolaci-da-Costa (2006), yeni teknolojik araçların sıkça kullanımlarının psikolojik etkilerinin, özünde birey genelde ise toplum üzerinde davranış ve alışkanlıklardaki değişimlerle yakın ilişki içerisinde olduğunu belirtmektedir. Dolayısıyla her ne kadar teknolojik gelişmelerin 
toplum yaşamında kolaylaştırıcı etkileri olduğu bilinse de diğer yandan olumsuz yönlerinin de dikkate alınması gerektiği söylenebilir.

Alanyazında nomofobi kavramının tanım ve belirtileri konusunda tartışmalar devam ederken nomofobinin belirtileri şu şekilde ifade edilmiştir (Tran, 2016):

- Bir veya daha fazla cihaza sahip olmak, düzenli olarak cep telefonu kullanmak ve onunla çok zaman harcamak, her zaman şarj cihazını yanında taşımak,

- Bireyin cep telefonu yakınlarda bulunmadığında ya da yanlış kullanıldığında ya da ăg kapsama alanı dışında olduğunda, pilin bitmesinden ve / veya internete erişilebilecek veri eksikliği nedeniyle kullanılamıyorsa kendisini endişeli ve gergin hissetmesi,

- Cihazın kullanımının yasak olduğu yerlerden ve durumlardan (toplu taşıma araçları, restoranlar, tiyatrolar ve havaalanları gibi) mümkün olduğunca uzak durmaya çalışması,

- Sürekli olarak mesaj veya aramaları görmek için telefonun ekranına bakmak, zil sesini dinlemek,

- Cep telefonunu asla kapatmamak, yatarken cihazı yanında bulundurmak,

- Kayg1 ve strese neden olacağı düşüncesiyle yüz yüze iletişim yerine, sürekli iletişim araçlarını kullanmak,

- Akıllı telefon satın almak için borç yapmak.

\section{Gelişmeleri Kaçırma Korkusu}

Gelişmeleri Kaçırma Korkusu (FOMO) kavramı, internetin ve özellikle akıllı telefonların yaşamımıza girmesiyle birlikte, "bireylerin sosyal ağlarda gelişmeleri kaçırma ve gelişmelerden haberdar olamama korkusu yaşamaları nedeniyle sosyal ağlarda oldukça uzun süreler geçirmelerine neden olan yeni bir bağımlılık türü" olarak tanımlanmaktadır (Przybylski, Murayama ve DeHaan, 2013. İnternet ile bağını koparmayan, neredeyse internetsiz yaşayamayacak hale gelen genç yetişkinlerin fiziksel olarak yorgunluk, yeme-içme, uykusuzluk ve odaklanma sorunu yaşayacakları açıktır. Bu durum ise yoğun bir fiziksel ve zihinsel performans gerektiren sportif etkinliklerin yapılmasında önemli engel teşkil edecektir.

\section{Yöntem}

\section{Araştırma Modeli}

$\mathrm{Bu}$ çalışma, nicel araştırma yöntemlerinden betimsel ve ilişkisel tarama modeliyle kurgulanmıştır.

\section{Çalışma Grubu}

Araştırmanın çalışma grubunu seçkisiz olmayan örneklem yöntemlerinden kolayda örneklem yoluyla belirlenen Türkiye'nin farklı şehirlerinde yer alan üniversitelerin spor eğitim kurumlarında öğrenim gören 240 kadın, 308 erkek olmak üzere toplam 548 lisanslı sporcu oluşturmaktadır. 


\section{Veri Toplama Araçları}

Araştırmada veri toplama aracı olarak araştırmacılar tarafından hazırlanan kişisel bilgi formu ile Nomofobi ölçeği, İnternet bağımlılık ölçeği ve Gelişmeleri Kaçırma Korkusu Ölçeği kullanılmıştır. Ölçeklere ilişkin güvenirlik analiz sonuçları Tablo 1'de sunulmuştur.

\section{Internet Bă̆ımlılık Ölçeği}

Orijinal adı "Skala zur Erfassung der Internetsucht" olan ölçek, Hahn ve Jerusalem (2001) tarafından geliştirilmiş, Şahin ve Korkmaz (2011) tarafından ise Türkçeye uyarlanmıştır. 5'li likert tipi olan ölçek 19 madde ve 3 alt boyuttan (Kontrol kaybı, Daha fazla online kalma isteği ve Sosyal ilişkilerde olumsuzluk) oluşmaktadır.

\section{Nomofobi Ölçeği}

Yıldırım ve Correira (2015) tarafından geliştirilen ölçeğin, Türkçe uyarlaması Yildirim ve diğerleri (2015) tarafından yapılmıştır. 20 maddeden oluşan ölçme aracı 7'li derecelemeye sahiptir. Ölçeğin değerlendirilmesi alt boyutlar üzerinden hesaplanmaktadır. Çevrimiçi olamama, iletişimi kaybetme, cihazdan yoksunluk ve bilgiye ulaşamama olmak üzere dört alt boyuttan oluşmaktadır.

\section{Gelişmeleri Kaçırma Korkusu Ölçeği (GKKÖ)}

Ölçme aracı Przybylski (2013) tarafından geliştirilmiş, Gökler ve diğerleri (2016) tarafından Türkçe'ye uyarlanmış, 10 sorudan oluşan beşli Likert tipi bir ölçektir. Ölçme aracının değerlendirmesi toplam puan üzerinden yapılmaktadır. Katılımcıların ölçekten aldıkları puan 10-50 arasında değişmekte olup, ölçeğin kesim puanı yoktur. Ölçek kişilerin kendi yaşamlarıyla ilgili değerlendirmeleri içermektedir. Ölçme aracından alınan puan arttıkça bireylerin gelişmeleri kaçırma korkusunun olma olasılığının arttığı ifade edilmektedir (Gökler ve diğerleri, 2016).

Tablo 1. Araştırmada Kullanılan Ölçme Araçlarına İlişkin Güvenirlik Katsayıları

\begin{tabular}{llc}
\hline Faktörler & Çevrimiçi olamama & $\begin{array}{c}\text { Mevcut araştırma için } \\
\text { Güvenirlik }(\boldsymbol{\alpha}) \\
\text { Katsayıları }\end{array}$ \\
\hline \multirow{3}{*}{ Nomofobi Ölçeği } & İletişimi kaybetme & .906 \\
& Cihazdan yoksunluk & .925 \\
& Bilgiye ulaşamama & .836 \\
İnternet Bağımlılık Ölçeği & Kontrol Kaybı & .922 \\
& Daha fazla online kalma isteği & .824 \\
Gelişmeleri Kaçırma Korkusu & Sosyal iliş̧ilerde olumsuzluk & .861 \\
Ölçeği & & .874 \\
\cline { 2 - 2 } & & .824 \\
\hline
\end{tabular}




\section{Verilerin Toplanması ve Analizi}

Elde edilen verilerin istatistiksel analizlerinde JASP ve SPSS istatistik programları kullanılmıştır. Verilerin istatistiksel gösterimleri aritmetik ortalama ve yüzde ile gerçekleştirilmiştir. Normallik dağılımı için basıklık ve çarpıklık değerleri (+1 ile -1) dikkate alınmıştır (Byrne, 2010). Verilerin normal dağılım göstermesi nedeniyle verilerin analizinde Independent T testi, One-Way Anova, Pearson korelasyon ve Çoklu doğrusal regresyon testi kullanılmıştır.

\section{Bulgular}

Araştırmanın bu bölümünde istatistiksel analizler neticesinde elde edilen bulgulara ilişkin tablo ve yorumlara yer verilmiştir.

Tablo 2. Tanımlayıcı İstatistikler

\begin{tabular}{lllll}
\hline Değişkenler & Gruplar & f & \multicolumn{1}{c}{$\mathbf{o}$} & n \\
\hline \multirow{2}{*}{ Cinsiyet } & Kadın & 240 & 43,8 & \multirow{2}{*}{548} \\
& Erkek & 308 & 56,2 & \\
Yaşadı̆̆ınız Çevre & Büyükşehir & 238 & 43,4 & \\
& İl & 217 & 39,6 & 548 \\
& İlçe & 67 & 12,2 & \\
Kimlerle yaşamaktasınız? & Köy/Kasaba & 26 & 4,7 & 548 \\
& Aile & 231 & 42,2 & \\
Cep telefonu yanında & Yurt & 131 & 23,9 & \multirow{2}{*}{548} \\
olmadığındaki duygu durumu & Ev Arkadaşı & 185 & 33,8 & \\
Sosyal medya hesabı olan ve & Diğer & 1 & 0,2 & \\
olmayan & Olumlu & 138 & 25,2 & \multirow{2}{*}{548} \\
& Olumsuz & 410 & 74,8 & \\
& Evet & 527 & 96,2 & \multirow{2}{*}{548} \\
& Hayır & 21 & 3,8 & \\
İnternet kullanım amacı & Araştırma & 54 & 9,9 & \\
& Eğlence & 108 & 19,7 & \\
& Bilgilendirme & 134 & 24,5 & \multirow{2}{*}{548} \\
& İletişim & 79 & 14,4 & \\
& Sosyalleşme & 16 & 2,9 & \\
& Zaman geçirme & 154 & 28,1 & \\
& Yalnızlık & 3 & 0,5 & \\
\hline
\end{tabular}

Tablo 2 incelendiğinde araştırmaya katılan katılımcıların \%56,2'sinin erkek, \%43,8'inin kadın olduğu; yaklaşık \%80 katılımcının büyükşehir veya ilde, \% 42'sinin ise ailesiyle yaşadığı tespit edilmiştir. Ayrıca katılımcılara cep telefonlarının yanında olmadığında nasıl bir duygu durumuna sahip olduğu sorgulanmış \%74,8 katılımcı olumsuz duygu durumuna sahip olduklarını belirtmişlerdir. Diğer yandan katılımcıların \%96,2'sinin herhangi bir sosyal medya aracına sahip olduğu ve \%28,1 katılımcı zaman geçirmek amacıyla internet kullandıklarını ifade etmişlerdir. 
Tablo 3. Tanımlayıcı İstatistikler (devamı)

\begin{tabular}{lccccc}
\hline Değişkenler & n & Min. & Maks. & $\overline{\boldsymbol{x}}$ & S \\
\hline Yaş & 548 & 17 & 35 & 21,602 & 2,69 \\
Gelir & 548 & 0 & 10000 & 1167,030 & 1351,00 \\
Günlük internette vakit geçirme (saat) & 548 & 1 & 5 & 4,872 & 2,80 \\
İnternet kullanım süresi (Ay) & 548 & 12 & 720 & 96,520 & 67,15 \\
\hline
\end{tabular}

Katılımcıların 21,602 $\pm 2,69$ yaş ortalamasına ve 1167,03 \pm 1351 TL gelire sahip oldukları görülmüştür. Ayrıca katılımcıların 4,872 saat günlük internet kullanım süresine sahip oldukları tespit edilmiştir.

Tablo 4. Katılımcıların Duygu Durumlarına Göre GKK, Nomofobi ve İnternet Bağımlılı̆̆ Alt Boyutları Arasındaki Farklar (T testi)

\begin{tabular}{|c|c|c|c|c|c|c|c|}
\hline Değişkenler & $\begin{array}{l}\text { Duygu } \\
\text { durumu }\end{array}$ & $\mathrm{N}$ & $\bar{x}$ & $S$ & sd & $\mathrm{t}$ & $\mathrm{p}$ \\
\hline Gelişmeleri Kaçırma & Olumlu & 138 & 25,195 & 8,525 & \multirow{2}{*}{207,211} & \multirow{2}{*}{$-4,044$} & \multirow{2}{*}{0,000} \\
\hline Korkusu & Olumsuz & 410 & 28,465 & 7,226 & & & \\
\hline \multirow{2}{*}{ Kontrol kaybı } & Olumlu & 138 & 2,207 & 0,953 & \multirow{2}{*}{546} & \multirow{2}{*}{$-6,808$} & \multirow{2}{*}{0,000} \\
\hline & Olumsuz & 410 & 2,811 & 0,885 & & & \\
\hline \multirow{2}{*}{ Online kalma isteği } & Olumlu & 138 & 2,371 & 1,010 & \multirow{2}{*}{546} & \multirow{2}{*}{$-6,302$} & \multirow{2}{*}{0,000} \\
\hline & Olumsuz & 410 & 3,017 & 1,052 & & & \\
\hline \multirow{2}{*}{$\begin{array}{l}\text { Sosyal ilişkilerde } \\
\text { olumsuzluk }\end{array}$} & Olumlu & 138 & 1,921 & 0,971 & \multirow{2}{*}{546} & \multirow{2}{*}{$-3,101$} & \multirow{2}{*}{0,002} \\
\hline & Olumsuz & 410 & 2,225 & 1,004 & & & \\
\hline \multirow{2}{*}{ Bilgiye ulaşamama } & Olumlu & 138 & 3,275 & 1,610 & \multirow{2}{*}{546} & \multirow{2}{*}{$-4,955$} & \multirow{2}{*}{0,000} \\
\hline & Olumsuz & 410 & 4,045 & 1,567 & & & \\
\hline \multirow{2}{*}{ Cihazdan yoksunluk } & Olumlu & 138 & 2,687 & 1,394 & \multirow{2}{*}{546} & \multirow{2}{*}{$-7,195$} & \multirow{2}{*}{0,000} \\
\hline & Olumsuz & 410 & 3,623 & 1,298 & & & \\
\hline \multirow{2}{*}{ İletişimi kaybetme } & Olumlu & 138 & 3,390 & 1,549 & \multirow{2}{*}{546} & \multirow{2}{*}{$-4,977$} & \multirow{2}{*}{0,000} \\
\hline & Olumsuz & 410 & 4,168 & 1,602 & & & \\
\hline \multirow{2}{*}{ Çevrimiçi olamama } & Olumlu & 138 & 2,629 & 1,564 & \multirow{2}{*}{546} & \multirow{2}{*}{$-4,051$} & \multirow{2}{*}{0,000} \\
\hline & Olumsuz & 410 & 3,236 & 1,508 & & & \\
\hline
\end{tabular}

Katılımcıların duygu durumları ile Nomofobi Ölçeği, Netlessfobi Ölçeği, Fomo Ölçeği alt boyutları arasındaki farkı incelemek üzere yapılan fark testi bulguları Tablo 2'de gösterilmiştir. Tablo incelendiğinde GKK toplam $(\mathrm{t}=-4,044 ; \mathrm{p}=0,00)$, kontrol kaybı $(\mathrm{t}=-6,808$; $\mathrm{p}=0,00)$, online kalma isteği $(\mathrm{t}=-6,302 ; \mathrm{p}=0,00)$, sosyal ilişkilerde olumsuzluk $(\mathrm{t}=-3,101 \mathrm{p}=0,002)$, bilgiye ulaşamama $(t=-4,955 ; p=0,00)$, cihazdan yoksunluk $(t=-7,195 ; p=0,00)$, iletişimi kaybetme $(t=-4,977 ; p=0,00)$ ve çevrimiçi olamama $(t=-4,051 ; p=0,00)$ alt boyutlarında olumsuz duygu durumu lehine anlamlı fark tespit edilmiştir. 
Tablo 5. Yaşanılan Çevreye göre GKK, Nomofobi ve Netlessfobi Ölçekleri Alt Boyutlarına İlişkin ANOVA Testi Sonuçları

\begin{tabular}{|c|c|c|c|c|c|c|c|c|c|c|c|}
\hline & Gruplar & $\mathrm{N}$ & $\bar{x}$ & $S$ & Varyansin Kay. & KT & SD & $\mathrm{KO}$ & $\mathrm{F}$ & $\mathrm{p}$ & Fark grup \\
\hline GKK & 1-Büyükşehir & 238 & 27,723 & 7,763 & & & & & & & \\
\hline \multirow[t]{3}{*}{ toplam } & $2-\dot{I l}$ & 217 & 27,203 & 7,762 & Grup arası & 150,836 & 3 & 50,279 & ,848 & ,468 & \\
\hline & 3-İlçe & 67 & 28,030 & 7,313 & Grup içi & 32269,06 & 544 & 59,318 & & & \\
\hline & 4- Köy/Kasaba & 26 & 29,577 & 7,601 & Toplam & 32419,9 & 547 & & & & \\
\hline Kontrol & 1-Büyükşehir & 238 & 2,710 & 0,962 & & & & & & & \\
\hline \multirow[t]{3}{*}{ kayb1 } & $2-\dot{I l}$ & 217 & 2,594 & 0,895 & Grup arası & 2,258 & 3 & 0,753 & ,852 & ,466 & \\
\hline & 3-İlçe & 67 & 2,631 & 0,967 & Grup içi & 480,385 & 544 & 0,883 & & & \\
\hline & 4- Köy/Kasaba & 26 & 2,819 & 1,027 & Toplam & 482,643 & 547 & & & & \\
\hline Online & 1-Büyükşehir & 238 & 2,917 & 1,086 & & & & & & & \\
\hline kalma & $2-\dot{I l}$ & 217 & 2,754 & 1,053 & Grup arası & 4,919 & 3 & 1,64 & 1,413 & 238 & \\
\hline \multirow[t]{2}{*}{ isteği } & 3-İlçe & 67 & 2,862 & 1,101 & Grup içi & 631,173 & 544 & 1,16 & & & \\
\hline & 4- Köy/Kasaba & 26 & 3,115 & 1,136 & Toplam & 636,092 & 547 & & & & \\
\hline \multirow{4}{*}{$\begin{array}{l}\text { Sosyal } \\
\text { ilişkilerde } \\
\text { olumsuzluk }\end{array}$} & 1-Büyükşehir & 238 & 2,220 & 1,032 & & & & & & & \\
\hline & $2-\dot{I l}$ & 217 & 2,042 & 0,956 & Grup arası & 5,248 & 3 & 1,749 & 1,741 & 157 & \\
\hline & 3-İlçe & 67 & 2,146 & 0,998 & Grup içi & 546,568 & 544 & 1,005 & & & \\
\hline & 4- Köy/Kasaba & 26 & 2,394 & 1,109 & Toplam & 551,817 & 547 & & & & \\
\hline
\end{tabular}

Tablo 5 incelendiğinde, gelişmeleri kaçırma korkusu ve nomofobi ölçeklerinin yaşanılan çevre değişkeni bakımından farklılık göstermemektedir ( $\mathrm{p}>$.05). 
Tablo 5 devamı. Yaşanılan Çevreye göre GKK, Nomofobi ve Netlessfobi Ölçekleri Alt Boyutlarına İlişkin ANOVA Testi Sonuçları

\begin{tabular}{|c|c|c|c|c|c|c|c|c|c|c|c|}
\hline & Gruplar & $\mathrm{N}$ & $\bar{x}$ & $S$ & Varyansin Kay. & KT & SD & $\mathrm{KO}$ & $\mathrm{F}$ & $\mathrm{p}$ & Fark grup \\
\hline \multirow{4}{*}{$\begin{array}{l}\text { Bilgiye } \\
\text { ulaşamama }\end{array}$} & 1-Büyükşehir & 238 & 3,804 & 1,637 & & & & & \multirow{4}{*}{ 710 } & \multirow{4}{*}{,546 } & \\
\hline & $2-\dot{I l}$ & 217 & 3,831 & 1,578 & Grup arası & 5,544 & 3 & 1,848 & & & \\
\hline & 3-İlçe & 67 & 3,925 & 1,647 & Grup içi & 1416,085 & 544 & 2,603 & & & \\
\hline & 4- Köy/Kasaba & 26 & 4,269 & 1,600 & Toplam & 1421,629 & 547 & & & & \\
\hline \multirow{4}{*}{$\begin{array}{l}\text { Cihazdan } \\
\text { yoksunluk }\end{array}$} & 1-Büyükşehir & 238 & 3,484 & 1,429 & & & & & \multirow{4}{*}{2,983} & \multirow{4}{*}{,031 } & \multirow{4}{*}{$1-2$} \\
\hline & $2-\dot{I l}$ & 217 & 3,188 & 1,307 & Grup arası & 16,942 & 3 & 5,647 & & & \\
\hline & 3-İlçe & 67 & 3,528 & 1,433 & Grup içi & 1029,738 & 544 & 1,893 & & & \\
\hline & 4- Köy/Kasaba & 26 & 3,815 & 1,286 & Toplam & 1046,681 & 547 & & & & \\
\hline \multirow{4}{*}{$\begin{array}{l}\text { İletişimi } \\
\text { kaybetme }\end{array}$} & 1-Büyükşehir & 238 & 4,034 & 1,572 & & & & & \multirow{4}{*}{2,209} & \multirow{4}{*}{,086 } & \\
\hline & $2-\dot{I l}$ & 217 & 3,815 & 1,619 & Grup arası & 17,36 & 3 & 5,787 & & & \\
\hline & 3-İlçe & 67 & 4,015 & 1,755 & Grup içi & 1424,951 & 544 & 2,619 & & & \\
\hline & 4- Köy/Kasaba & 26 & 4,622 & 1,669 & Toplam & 1442,312 & 547 & & & & \\
\hline \multirow{4}{*}{$\begin{array}{l}\text { Çevrimiçi } \\
\text { olamama }\end{array}$} & 1-Büyükşehir & 238 & 3,280 & 1,553 & & & & & \multirow{4}{*}{3,302} & \multirow{4}{*}{,020 } & \multirow{4}{*}{$1-2$} \\
\hline & 2-ìl & 217 & 2,839 & 1,493 & Grup arası & 23,32 & 3 & 7,773 & & & \\
\hline & 3-İlçe & 67 & 3,096 & 1,532 & Grup içi & 1280,645 & 544 & 2,354 & & & \\
\hline & 4- Köy/Kasaba & 26 & 3,292 & 1,708 & Toplam & 1303,966 & 547 & & & & \\
\hline
\end{tabular}

Anova sonuçları incelendiğinde, Netlessfobi ölçeği alt boyutlarından cihazdan yoksunluk $\left(\mathrm{F}_{(3,544)}=2.98\right.$, $\left.\mathrm{p}<.05\right)$ ve çevrimiçi olamama $\left(\mathrm{F}_{(3,544)}=2.98, \mathrm{p}<.05\right)$ alt boyutlarında anlamlı farklılıklar tespit edilmiştir. Büyükşehirde yaşayan bireylerin cihazdan yoksunluk ve çevrimiçi olamama düzeyleri yaşanılan diğer yerlere göre yüksek tespit edilmiştir. 
Tablo 6. Gelişmeler Kaçırma Korkusu, Netlessfobi ve Nomofobi'ye İlişkin Korelasyon Analiz Sonuçları

\begin{tabular}{lcccc}
\hline Değişkenler & $\begin{array}{c}\text { Bilgiye } \\
\text { ulaşamama }\end{array}$ & $\begin{array}{c}\text { Cihazdan } \\
\text { yoksunluk }\end{array}$ & $\begin{array}{c}\text { İletişimi } \\
\text { kaybetme }\end{array}$ & $\begin{array}{c}\text { Çevrimiçi } \\
\text { olamama }\end{array}$ \\
\hline $\begin{array}{l}\text { Gelişmeleri Kaçırma } \\
\text { Korkusu }\end{array}$ &, $400^{*}$ &, $458^{*}$ &, $430^{*}$ &, $459^{*}$ \\
$\begin{array}{l}\text { Kontrol kaybı } \\
\text { Online kalma isteği }\end{array}$ &, $460^{*}$ &, $624^{*}$ &, $430^{*}$ &, $578^{*}$ \\
$\begin{array}{l}\text { Sosyal ilişkilerde } \\
\text { olumsuzluk }\end{array}$ &, $286^{*}$ &, $573^{*}$ &, $383^{*}$ &, $510^{*}$ \\
${ }^{*} \mathrm{p}=.05, \mathrm{n}=548$ & & &, $278^{*}$ &, $572^{*}$ \\
\end{tabular}

Tablo 6 incelendiğinde gelişmeleri kaçırma korkusu ile bilgiye ulaşamama, cihazdan yoksunluk, iletişimi kaybetme ve çevrimiçi olamama arasında pozitif yönde orta düzeyde ilişki tespit edilmiştir. İnternet bağımlılık ölçeği alt boyutlarından kontrol kaybı, online kalma isteği ve sosyal ilişkilerde olumsuzluk alt boyutlarında pozitif ve orta düzey ilişkiler bulunmuştur. Genel olarak incelendiğinde en yüksek korelasyonun kontrol kaybı ile cihazdan yoksunluk arasında ( $r=.624)$; en düşük korelasyonun ise sosyal ilişkilerde olumsuzluk ve iletişimi kaybetme arasında ( $\mathrm{r}=.278)$ olduğu görülmüştür.

Tablo 7. İnternet Bağımlılı̆̆ı Kontrol Kaybı Alt Boyutunun Yordanmasına İlişkin Çoklu Doğrusal Regresyon Analizi

\begin{tabular}{|c|c|c|c|c|c|c|c|}
\hline Değişkenler & B & $\begin{array}{c}\text { Standart } \\
\text { Hata в }\end{array}$ & B & $\mathbf{t}$ & $\mathbf{p}$ & İkili r & Kismi r \\
\hline Sabit & ,486 & ,112 & - & 4,318 & ,000 & - & - \\
\hline Bilgiye ulaşamama & ,046 & ,024 & ,079 & 1,919 & ,056 & 460 & ,082 \\
\hline Cihazdan yoksunluk & ,232 & ,035 & ,342 & 6,589 & ,000 & ,624 & ,272 \\
\hline İletişimi kaybetme &,- 040 & ,025 &,- 069 & $-1,611$ & 108 & ,430 &,- 069 \\
\hline Çevrimiçi olamama & 120 & ,028 & 198 & 4,368 & ,000 &, 578 & ,184 \\
\hline Gelişmeleri kaçırma korkusu & ,036 & ,004 & 296 & 8,240 & ,000 &, 545 & ,334 \\
\hline $\mathrm{R}^{2}=0.496$ & & & & & & & \\
\hline$F_{(5-542)}=106,518, \quad p=0.00$ & & & & & & & \\
\hline
\end{tabular}

Tablo 7'de Akıllı Telefon Bağımlılı̆̆ı alt boyutları ile Gelişmeleri Kaçırma Korkusu değişkenlerine göre İnternet Bağımlılı̆̆ı ölçeği alt boyutlarından kontrol kaybının yordanmasına ilişkin regresyon analizi sonuçları verilmiştir. 
Bilgiye ulaşamama, cihazdan yoksunluk, iletişimi kaybetme, çevrimiçi olamama ve gelişmeleri kaçırma korkusu değişkenleri birlikte kontrol kaybı puanları ile orta düzeyde anlamlı bir ilişki göstermektedir $\left(\mathrm{R}=0.704, \mathrm{R}^{2}=0.496, \mathrm{p}<.00\right)$. Modelin açıklama gücü olarak ifade edilen $\mathrm{R}^{2}$ değeri kontrol kaybındaki değişkenliğin yaklaşı \% 50'sinin modelde yer alan bağımsız değişkenler tarafından yordandığı şeklinde yorumlanır. Açıklanamayan varyansların ise kontrol kaybını etkileyen başka bağımsız değişkenlerin göstergesi olabileceği ifade edilebilir.

Tablo 8. İnternet Bağımlılığı Online Kalma İsteği Alt Boyutunun Yordanmasına İlişkin Çoklu Doğrusal Regresyon Analizi

\begin{tabular}{|c|c|c|c|c|c|c|c|}
\hline Değişkenler & B & $\begin{array}{l}\text { Standart Hata } \\
\text { B }\end{array}$ & B & $\mathbf{t}$ & p & İkili r & K1smi r \\
\hline Sabit & 812 & ,143 & - & 5,663 & ,000 & - & - \\
\hline Bilgiye ulaşamama & ,069 & ,031 & 103 & 2,248 & ,025 & ,428 & ,096 \\
\hline Cihazdan yoksunluk & 278 & ,045 & ,357 & 6,200 & ,000 &, 573 & ,257 \\
\hline İletişimi kaybetme &,- 046 & ,031 &,- 069 & $-1,452$ & , 147 & ,383 &,- 062 \\
\hline Çevrimiçi olamama & 115 & ,035 & , 165 & 3,276 & ,001 & ,510 & 139 \\
\hline Gelişmeleri kaçırma korkusu & ,024 & ,006 & ,171 & 4,294 & ,000 & 422 & 181 \\
\hline $\mathrm{R}=0.615, \quad \mathrm{R}^{2}=0.378$ & & & & & & & \\
\hline $\mathrm{F}_{(5-542)}=65,989, \quad \mathrm{p}=0.00$ & & & & & & & \\
\hline
\end{tabular}

Tablo 8'de Akıllı Telefon Bağımlılı̆̆ı alt boyutları ile Gelişmeleri Kaçırma Korkusu değişkenlerine göre İnternet Bağımlılığı ölçeği alt boyutlarından online kalma isteğinin yordanmasına ilişkin regresyon analizi sonuçları verilmiştir.

Bilgiye ulaşamama, cihazdan yoksunluk, iletişimi kaybetme, çevrimiçi olamama ve gelişmeleri kaçırma korkusu değişkenleri birlikte kontrol kaybı puanları ile orta düzeyde anlamlı bir ilişki göstermektedir $\left(\mathrm{R}=0.615, \mathrm{R}^{2}=0.378, \mathrm{p}<.00\right)$. Modelin açıllama gücü olarak ifade edilen $\mathrm{R}^{2}$ değeri kontrol kaybındaki değiş̧kenliğin yaklaşık \%38'inin modelde yer alan bağımsız değişkenler tarafından yordandığı şeklinde yorumlanır. 
Tablo 9. İnternet Bağımlılı̆̆ Sosyal İlişkilerde Olumsuzluk Alt Boyutunun Yordanmasına İlişkin Çoklu Doğrusal Regresyon Analizi

\begin{tabular}{|c|c|c|c|c|c|c|c|}
\hline Değişkenler & B & $\begin{array}{c}\text { Standart } \\
\text { Hata в }\end{array}$ & B & $\mathbf{t}$ & $\mathbf{p}$ & İkili $\mathbf{r}$ & Kismi r \\
\hline Sabit & 492 & ,132 & - & 3,716 & ,000 & - & - \\
\hline Bilgiye ulaşamama &,- 028 & ,028 &,- 046 & $-1,005$ & 315 & ,286 &,- 043 \\
\hline Cihazdan yoksunluk & 203 & 041 & 279 & 4,891 & ,000 &, 515 & ,206 \\
\hline İletişimi kaybetme &,- 106 & ,029 &,- 172 & $-3,654$ & ,000 & 278 &,- 155 \\
\hline Çevrimiçi olamama & 256 & ,032 & ,394 & 7,917 & ,000 &, 572 & ,322 \\
\hline Gelişmeleri kaçırma korkusu &, 026 & ,005 & ,197 & 5,001 &, 000 &, 414 & ,210 \\
\hline $\begin{array}{ll}R=0.624, & R^{2}=0.390 \\
F(5-542)=69,926, & p=0.00\end{array}$ & & & & & & & \\
\hline
\end{tabular}

Tablo 9'da Akıllı Telefon Bağımlılı̆̆ı alt boyutları ile Gelişmeleri Kaçırma Korkusu değişkenlerine göre İnternet Bağımlılı̆̆ı ölçeği alt boyutlarından sosyal ilişkilerde olumsuzluğun yordanmasına ilişkin regresyon analizi sonuçları verilmiştir.

Bilgiye ulaşamama, cihazdan yoksunluk, iletişimi kaybetme, çevrimiçi olamama ve gelişmeleri kaçırma korkusu değişkenleri birlikte kontrol kaybı puanları ile orta düzeyde anlamlı bir ilişki göstermektedir $\left(\mathrm{R}=0.624, \mathrm{R}^{2}=0.390, \mathrm{p}<.00\right)$. Modelin açıllama gücü olarak ifade edilen $\mathrm{R}^{2}$ değeri kontrol kaybındaki değişkenliğin \%40'ının modelde yer alan bağımsız değişkenler tarafından yordandığ 1 şeklinde yorumlanır.

\section{Tartışma, Sonuç ve Öneriler}

Günümüz teknoloji çağında, kişisel bilgisayarları (PC'leri), tabletleri ve cep telefonlarını içeren yeni teknolojilerin ve sanal iletişimin artan kullanımı, bireylerin günlük alışkanlıklarında ve davranışlarında önemli değişimlere neden olabilmektedir. Öyle ki mevcut araştırma sonuçları genel anlamda genç yetişkinlerin teknolojik araçlara yönelik eğilimlerinin olduğunu göstermektedir.

Dijital medya kullanımı ile zihinsel sağlık arasındaki ilişkiler, birkaç yıl boyunca ağırlıklı olarak psikologlar, sosyologlar, antropologlar ve tıbbi uzmanlar gibi çeşitli araştırmacılar tarafından derinlemesine irdelenmiş ve birtakım farklı sonuçlar ortaya çıkmıştır (Bashir ve Bhat, 2017; Orzech, Grandner, Roane ve Carskadon, 2016).

Teknolojinin gelişim göstermesiyle birlikte aşırı bir şekilde dijital cihaz kullanımı bağımlılık oluşturmaya başlamıştır. Bağımlılık her ne kadar her yaştan her kesimden bireyin sorunu olsa da çocukları ve gençleri daha çok etkilemektedir. Dijital yerliler olarak da ifade edilen çocuklar ve gençlerin çağın dijital hastalıklarına daha kolay bir şekilde yakalanmaktadır. Bu noktada şüphesiz internet teknolojisi ve akıllı telefonların yeri oldukça büyüktür. İnternet bağımlılığı (netlessfobi), cep telefonu bağımlılığı (Nomofobi) ve gelişmeleri kaçırma korkusu (Fomo) gibi aşırı bağımlılıklar, hastalık derecesinde günümüz toplumu üzerinde büyük bir tehdit durumuna gelmiştir. Özellikle mobil internet kullanımının yaygınlaşmasıyla bilgiye erişimin hızlandığ1 (Asongu ve Nwachukwu, 2017; Arpaci, 2017; Arpaci, 2016) ve bu durumun genç yetişkinlerin mobil teknoloji aracılığıyla iletişim ve etkileşim ortamını arttırdığı söylenebilir. King vd., (2014) kullanıcıların elinde cep telefonu olmadığında kendilerini yalnız hissettiğini 
ifade etmektedir. Ayrıca çalışmada bireylerin toplum içerisinde yalnız kalmalarının Nomophobia sorununa katkıda bulunduğu belirtilmiştir. Yıldız, Polat ve Güzel'in (2018) "Espor oyuncularının internet bağımlılık düzeyleri ve oyun motivasyonları" adlı sporcular üzerine yapmış oldukları araştırmada, bireylerin eğlence amaçlı olarak katılmaya başladıkları e-spor etkinliklerinin oyun motivasyonunu ve devamında internet bağımlılı̆̆ını arttırdığ belirtilmiştir. Bedir, Erhan ve Akkuş (2019) tarafından sporcular üzerinde yapılan "Bilgisayar Oyun Bă̆ımlılığı Sporcuların Psikolojik Becerilerini Etkiler Mi?" adlı diğer bir çalışmada ise video oyun bağımlılığının sporcuların psikolojik becerilerini olumsuz yönde etkilediğini göstermektedir. Sporcuların psikolojik durumları müsabaka öncesi, müsabaka sırasında ve sonrasında sporcu performansını etkileyen önemli bir unsur olarak dikkate alınmalıdır. Diğer bir çalışmada ise, Esentaş, Güzel ve Vural (2018), dijital sporların Türkiye' de hızla yaygınlaşan bir akım olduğunu ve olumlu yönde değerlendirildiğinde kısıtlı zamanlarda aktif yaşamı destekleyebildiği fakat iyi değerlendirilemediğinde ise bir bağımlılık etkisi yaratabileceğini belirtmişlerdir. Ercan ve Tekin (2019) ise beden eğitimi öğretmenleri üzerinde yapmış oldukları çalışmada, öğretmenlerde nomofobinin hızla yayıldığını hem kendi yaşam kalitelerini arttırma hem de öğrencilerin nomofobi olmalarını engelleyici tedbir almaları açısından beden eğitimi öğretmenlerinde farkındalık yaratılması gerektiğini vurgulamışlardır.

Araştırma sonuçları katılımcıların gelişmeleri kaçırma korkusu, nomofobi ölçeği ve internet bağımlılığı ölçeği alt boyutlarının katılımcıların olumsuz duygu durumlarına göre farklılaştığı ifade edilebilir. Dijital bağımlılık ve diğer dijital hastalıklar yetişkin sporcu gençleri de derinden etkilemekte, odaklanma, motivasyon ve başarı düzeylerinde düşüklükler meydana getirmektedir. Özellikle yetişkin sporcu gençlerin sürekli olarak online olma ve sanal ortamda iletişim kurma arzusu, mesleki başarılarında da kayıplar yaşatmaktadır. Bilgiye ulaşamama, kontrol kaybı gibi unsurlar da genç yetişkinleri bekleyen diğer korku unsurlarıdır. Bu durum bireylerin olumsuz duygu durumlarının ortaya çıkmasına neden olabilmektedir. Özellikle büyük şehirlerde yaşayanların bu sorunlarla daha fazla karşı karşıya kaldığı görülmüş ve metropol hayatının dijital iletişim üzerinden şekillendiği açık bir şekilde ortaya çıkmıştır. Araştırmada dikkat çeken bir diğer nokta ise kadın ve erkekler arasındaki bağımlılık düzeyinde gözle görülür bir fark olmadığıdır. Elde edilen sonuçlar incelendiğinde bu problemin hem kadınlar hem de erkekler tarafından karşılaşılan temel bir sorun olduğu görülmektedir.

Diğer bir bulguda ise netlessfobi ölçeği alt boyutlarından cihazdan yoksunluk ve çevrimiçi olamama alt boyutlarında anlamlı farklılıklar tespit edilmiştir. Büyükşehirde yaşayan bireylerin cihazdan yoksunluk ve çevrimiçi olamama düzeyleri yaşanılan diğer yerlere göre yüksek tespit edilmiştir. Alanyazında yapılan bir çalışmada sportif etkinliklere katılan bireylerin kendi kendine kontrol, güven, sosyal beceriler ve yeni ilişki kurmada daha başarılı oldukları ifade edilmiştir (Holt vd., 2011; Hiremath, 2019). Değişen toplumsal koşullar bireylerin yaşam biçimlerinde de farklllıklara neden olabilmektedir. Özellikle kentleşme bireylerin toplumdan soyut bir yaşama sürüklenmesinde önemli bir etkendir. Bu gibi faktörlerin bireylerin teknolojik gelişmelerin ürünlerine yönelik bağımlılıklarını arttırdığ düşünülebilir. 1998 yılında Young'ın (1998b) yapmış olduğu bir çalışmada, günümüzde bireylerin sıklıkla kullandığı müzik, spor, alışveriş, finans vb., içerik imkanı sunan alanların tamamı olmasa da bireye zevk veren bu alanların oyun, kumar, alışveriş ve seks gibi bağımlılıklara sebep olabileceği ifade edilmiştir. Bu bağımlılıkların yanı sıra günümüzde 
egzersiz bağımlılı̆̆ da bireyleri davranışsal boyutta etkileyen önemli unsurlardan birisi olarak düşünülebilir.

Araştırma neticesinde en dikkat çekici nokta; gelişmeleri kaçırma korkusu ile bilgiye ulaşamama, cihazdan yoksunluk, iletişimi kaybetme ve çevrimiçi olamama arasında pozitif yönde orta düzeyde ilişkinin tespit edilmesidir. İnternet bağımlılık ölçeği alt boyutlarından kontrol kaybı, online kalma isteği ve sosyal ilişkilerde olumsuzluk alt boyutlarında pozitif ve orta düzey ilişkiler bulunmuştur. Sporcular üzerine yapılan bir araştırmada, kişisel elektronik cihazların sporculardan uzaklaştırılması noktasında, sporcuların kendilerini endişeli hissettikleri belirtilmiştir (Jones vd., 2019).

Diğer bir önemli etki ise 21.yüzyıl gençlerinin teknolojik kuşağın bir ürünü olan e-spor olarak tanımlanan elektronik ortamlardaki spor oyunlarına hızlı bir şekilde uyum sağlamaya başlamalarıdır. Son zamanların popüler oyun ortamı olarak tanımlanan e-spor ise, gençlerin uzun vadede hareketsiz kalmalarına sebep olmakla birlikte neticede ortaya çıabilecek internet bağımlığı ise bilişsel ve davranışsal bağımlılığın bir alt kümesi olmasından dolayı özellikle genç kuşağın sosyal izolasyon yaşamalarında da önemli derecede etkiye sahiptir. Öyle ki Moody (2001) yapmış olduğu çalışmada bireylerin sosyal izolasyondan ziyade yüz yüze iletişim kurmalarının toplumsal yalnızlıktan uzaklaşmada etkili olduğu ifade edilmiştir. Dirik (2018) ise internet ve internet araçları kullanımının her ne kadar iletişimi arttırmaya yönelik bir teknoloji olsa da, bireyleri mutsuzluğa ve yalnızlığa iten bir özelliğe sahip olduğunu belirtmiştir.

Sonuç olarak dijital bağımlılık ve benzeri hastalıklarla çözüm noktasında dijital detoks oldukça önemlidir. Bireyin özellikle hafta sonları dijital detoks yapması, akıllı telefon orucu tutmaması büyük önem arz etmektedir. Bununla birlikte dijital okuryazarlık bir diğer önemli etmendir. Dijital medya aracılığıyla yayılan metinleri, mesajları görselleri doğru okumak ve anlamlandırmak da son derece mühimdir. Sıcak iletişim olarak ifade edilen yüz yüze iletişim kurulması da dijital hastalıklarla mücadele noktasında büyük avantajlar sağlayacaktır. Ayrıca gelişmeleri kaçırma korkusu ve nomofobinin, internet bağımlılığını etkileyen önemli bir unsur olduğu ifade edilebilir. Çalışmada gençlerin teknolojik araçların kullanımı noktasında ve aşırı internet kullanımı konusunda eğitimler verilmesi, kamu spotlarının bu noktada arttırılması önerilmektedir. Bu çözüm yollarıyla bilinçli teknoloji kullanımının teşvik edilmesi ve internet bağımlılı̆̆ının azaltılması hedeflenmektedir.

\section{Kaynakça}

Aktüel Psikoloji. (2013). Nomofobi nedir? Belirtileri nelerdir?. [Erişim adresi: http://www.aktuelpsikoloji.com/haber.php?haber_id=11388, erişim tarihi: 31.08.2019.]

Arpaci, I. (2016). Understanding and predicting students' intention to use mobile cloud storage services. Computers in Human Behavior 58, 150-157. Doi: 10.1016/j.chb.2015.12.067.

Arpaci, I. (2017). Antecedents and consequences of cloud computing adoption in education to achieve knowledge management. Computers in Human Behavior 70, 382-390. Doi: 10.1016/j.chb.2017.01.024. 
Asongu, S., \& Nwachukwu, J.C. (2017). Mobile phones in the diffusion of knowledge and persistence in inclusive human development in Sub-Saharan Africa. Information Development 33(3): 289-302. Doi: 10.1177/0266666916655189.

Bashir, H., \& Bhat, S.A. (2017). Effects of Social Media on Mental Health: A Review. International Journal of Indian Psychology, 4(3),125-131. Doi:10.25215/0403.134.

Bedir, D., Erhan, S.E., Akkuş, Y. (2019). Bilgisayar oyun bağımlılığı sporcuların psikolojik becerilerini etkiler mi?. Beden Ĕgitimi ve Spor Bilimleri Dergisi , 21(1-A) , 40-49.

Bimber, B., \& Copeland, L. (2013). Digital media and traditional political participation over time in the US. Journal of Information Technology \& Politics, 10(2), 125-137.

Boulianne, S. (2015). Social media use and participation: A meta-analysis of current research. Information, Communication ve Society, 18(5), 524-538.

Byrne, B. M. (2010). Structural equation modeling with AMOS: Basic concepts, applications, and programming (2nd ed.). New York, NY: Routledge Academic.

Davis, R. A. (2001). A cognitive-behavioral model of pathological Internet use. Computers in Human Behavior, 17, 187-195.

Davis, R. A., Flett, G. L., \& Besser, A. (2002). Validation of a new scale for measuring problematic internet use: implications for pre-employment screening. Cyberpsychology Behavior, 5(4), 331-345.

Dirik, D. (2018). Sosyal medya, sanal ortam ve yalnızlık. H. Yıldız (Ed.,) Sosyal medyanın iş yaşamındaki yeri (301-315) İçinde. İstanbul: Beta.

Eryılmaz, İ. (2018). Bilgi Toplumunun yeni korkuları: Nomofobi ve Netlessfobi. H. Yıldız (Ed.,) Sosyal medyanın iş yaşamındaki yeri (1-24) İçinde. İstanbul: Beta.

Ercan, Ö., \& Tekin, N. (2019). Beden eğitimi öğretmenlerinin nomofobi düzeylerinin incelenmesi. Journal of Global Sport and Education Research, 2(1), 24-34.

Esentaş, M., Güzel, P., \& Vural, M. (2018). Popüler kültürde rekreatif bir etkinlik olarak dijital sporlar. Atatürk Üniversitesi Beden Ĕ̆itimi ve Spor Bilimleri Dergisi, 20(1),71-79.

Gökler, M. E., Aydın, R., Ünal, E., \& Metintaş, S. (2016). Sosyal ortamlarda gelişmeleri kaçırma korkusu ölçeğinin Türkçe sürümünün geçerlilik ve güvenilirliğinin değerlendirilmesi. Anadolu Psikiyatri Dergisi, 17(1), 52-59.

Hahn A., Jerusalem M. (2001). Internetsucht - Reliabilität und Validität in der OnlineForschung. Theobald A., Dreyer M., Starsetzki T. (eds) In Online-Marktforschung. Gabler Verlag, Wiesbaden

Hiremath, C. (2019). Impact of sports on mental health. International Journal of Physiology, Nutrition and Physical Education, 2019; SP1: 14-18.

Holden, C. (2001). Behavioral addictions: do they exist? Science, 294(5544), 980-982.

Holt, N. L., Kingsley, B. C., Tink, L. N., \& Scherer, J. (2011). Benefits and challenges associated with sport participation by children and parents from low-income families. Psychology of sport and exercise, 12(5), 490-499.

Jones, M. J., Dawson, B., Eastwood, P. R., Halson, S. L., Miller, J., Murray, K., ... \& Peeling, P. (2019). Influence of Electronic Devices on Sleep and Cognitive Performance During Athlete 
Training Camps. Journal of strength and conditioning research, 1-9. doi:10.1519/jsc.0000000000002991.

Kemp, S. (2019). Global Digital 2019 reports. [Erişim Adresi: https://wearesocial.com.]

King, A. L. S., Valença, A. M., Silva, A. C. O., Baczynski, T., Carvalho, M. R., \& Nardi, A. E. (2013). Nomophobia: Dependency on virtual environments or social phobia? Computers in Human Behavior, 29(1), 140-144.doi:10.1016/j.chb.2012.07.025.

Kocabaş, D., \& Korucu, K. S. Dijital Çağın Hastalığ1 Nomofobi Üzerine Bir Araştırma. Avrasya Sosyal ve Ekonomi Araştırmaları Dergisi, 5(11), 254-268.

Moody, E. J. (2001). Internet use and its relationship to loneliness. CyberPsychology $\mathcal{E}$ Behavior, 4(3), 393-401. doi.org/10.1089/109493101300210303.

Nicolaci-da-Costa, A. M. (2006). Digital heads: The daily life in the era of information. Rio de Janeiro. Puc-Rio: Loyola.

Orzech, K. M., Grandner, M. A., Roane, B. M., \& Carskadon, M. A. (2016). Digital media use in the $2 \mathrm{~h}$ before bedtime is associated with sleep variables in university students. Computers in Human Behavior, 55, 43-50. doi:10.1016/j.chb.2015.08.049

Öztürk, U. C. (2015). Bağlantıda kalmak ya da kalmamak işte tüm korku bu: İnternetsiz kalma korkusu ve örgütsel yansımaları. Uluslararası Sosyal Araştırmalar Dergisi, 8(37);629-638.

Pea, R., Nass, C., Meheula, L., Rance, M., Kumar, A., Bamford, H., ... \& Zhou, M. (2012). Media use, faceto-face communication, media multitasking, and social well-being among 8-to 12year-old girls. Developmental Psychology, 48(2), 327-336.

Przybylski AK, Murayama K, DeHaan CR. Motivational, emotional, and behavioral correlates of Fear of Missing Out. Comput Human Behav 2013; 29(4):1841-1848.

Shotton, M. (1991). The costs and benefits of "computer addiction." Behaviour and Information Technology, 10(3), 219-230

Tang, G. \& Lee, F. L. F. (2013). Facebook use and political participation: The impact of exposure to shared political information, connections with public political actors, and network structural heterogeneity. Social Science Computer Review, 31(6), 763-773. doi:10.1177/0894439313490625.

Tran, D. (2016). Classifying nomophobia as smart-phone addiction disorder. UC Merced Undergraduate Research Journal,9(1).1-22. Retrieved from https://escholarship.org/uc/item/0pq332g4.

Yıldırım, C., \& Correia, A. P. (2015). Exploring The Dimensions of Nomophobia: Development and Validation of a Self-Reported Questionnaire. Computers in Human Behavior, 49, 130- 137.

Yıldız, H., ve Yıldız, B. (2016). Sanal kaytarma yapmak kötü bir şey değildir. Ama?. Harvard Business Review Türkiye, Eylül, 108-115.

Yıldız, K. (2016). Bilgi ve iletişim teknolojileri boyutuyla spor ve iletişim. Ankara: Nobel Akademik.

Yıldız, K., Polat, E., ve Güzel, P. (2018). Espor oyuncularının internet bağımlılık düzeyleri ve oyun motivasyonları üzerine bir araştırma. 16. Uluslararası Spor Bilimleri Kongresi Tam Metin Kitabı, 31 Ekim-3 Kasım 2018, Antalya. 
Yildirim, C. \& Correia A-P. (2015). Exploring the dimensions of nomophobia: Development and validation of a self-reported questionnaire. Computers in Human Behavior, 49, 130-137.

Yildirim, C., Sumuer, E., Adnan, M., \& Yildirim, S. (2015). A Growing Fear: Prevalence Of Nomophobia Among Turkish College Students. Information Development, 32(5), 1322- 1331.

Young, K. S. (1996). Internet addiction: The emergence of a new clinical disorder. Paper presented at the 104th Annual Meeting of the American Psychological Association, Toronto, Ontario, Canada.

Young, K. S. (1998a). Internet addiction: The emergence of a new clinical disorder. Cyberpsychology and Behavior, 1(3), 237-244.

Young, K. S. (1998b). Caught in the Net: How to recognize the signs of Internet addiction and a winning strategy for recovery. New York: John Wiley \& Sons. 